\title{
BMJ Open Qualitative accounts from Syrian health professionals regarding violations of the right to health, including the use of chemical weapons, in opposition- held Syria
}

Katherine H A Footer, ${ }^{1,2,3}$ Emily Clouse, ${ }^{1}$ Diana Rayes, ${ }^{2,3}$ Zaher Sahloul, ${ }^{4}$ Leonard S Rubenstein ${ }^{2,3}$

To cite: Footer KHA, Clouse E, Rayes D, et al. Qualitative accounts from Syrian health professionals regarding violations of the right to health, including the use of chemical weapons, in oppositionheld Syria. BMJ Open 2018;8:e21096. doi:10.1136/ bmjopen-2017-021096

- Prepublication history for this paper is available online. To view these files, please visit the journal online (http://dx.doi. org/10.1136/bmjopen-2017021096).

Received 18 January 2018 Revised 27 April 2018 Accepted 5 June 2018

\section{Check for updates}

(c) Author(s) (or their employer(s)) 2018. Re-use permitted under CC BY-NC. No commercial re-use. See rights and permissions. Published by BMJ.

${ }^{1}$ Department of Health Behavior and Society, Johns Hopkins Bloomberg School of Public Health, Baltimore, Maryland, USA

${ }^{2}$ Department of Epidemiology, Johns Hopkins Bloomberg School of Public Health,

Baltimore, Maryland, USA

${ }^{3}$ Center for Public Health and Human Rights, Johns Hopkins Bloomberg School of Public Health, Baltimore, Maryland, USA

${ }^{4}$ Christ Advocate Medical Center, Oak Lawn, Illinois, USA

Correspondence to Katherine H A Footer; kfooter1@jhu.edu

\section{ABSTRACT}

Objectives To explore the impact of the conflict, including the use of chemical weapons, in Syria on healthcare through the experiences of health providers using a public health and human rights lens.

Design A qualitative study using semi-structured interviews conducted in-person or over Skype using a thematic analysis approach.

Setting Interviews were conducted with Syrian health workers operating in opposition-held Syria in cooperation with a medical relief organisation in Gaziantep, Turkey. Participants We examined data from 29 semi-structured in-depth interviews with a sample of health professionals with current or recent work-related experience in opposition-controlled areas of Syria, including respondents to chemical attacks.

Results Findings highlight the health worker experience of attacks on health infrastructure and services in Syria and consequences in terms of access and scarcity in availability of essential medicines and equipment. Quality of services is explored through physicians' accounts of the knock-on effect of shortages of equipment, supplies and personnel on the right to health and its ethical implications. Health workers themselves were found to be operating under extreme conditions, in particular responding to the most recent chemical attacks that occurred in 2017, with implications for their own health and mental well-being. Conclusions The study provides unique insight into the impact war has had on Syrian's right to health through the accounts of a sample of Syrian health professionals, with continuing relevance to the current conflict and professional issues facing health workers in conflict settings.

\section{BACKGROUND}

The ongoing civil war in Syria has created one of the direst humanitarian crises of our time. ${ }^{2}$ Syria's healthcare system has been decimated and the healthcare community targeted as part of an ongoing military strategy by the Syrian government, now supported by Russian air power. ${ }^{2}$ Initiatives exist to assist

\section{Strengths and limitations of this study}

- This study uniquely explores the experiences of healthcare providers providing healthcare during the current conflict in Syria.

- The study revealed the ways in which the conflict has impacted health providers' ability to provide healthcare in accordance with patients' right health.

The findings have implications for capacity-building within humanitarian organisations to counter the challenges faced by Syria's health professionals.

- Interviews were limited to the experiences of a small sample of health workers working in opposition-held regions of Syria, including survivors of chemical attacks.

health providers operating in insecure environments, ${ }^{3} 4$ including intense advocacy against increasing attacks on healthcare in conflict settings. However, only a small body of research studies ${ }^{5}$ have unpacked the operational, professional and personal challenges health providers face, and none in Syria. In light of the recent allegations of chemical weapon use throughout Syria and the intimidation of medics speaking out by the Syrian government, the perspectives of healthcare workers could not be more pressing. ${ }^{67}$

Human rights organisations and the United Nations (UN) agencies have placed a spotlight on the Syrian government's assault on healthcare. ${ }^{6-14}$ Physicians for human rights documented 478 attacks on medical facilities and the killing of 830 medical personnel since the start of the conflict in 2011, the vast majority by the Syrian government and allied forces. ${ }^{8}$ Through to December 2017, Syria has experienced 492 separate attacks on health facilities, ${ }^{15}$ while at the commencement of this research in 2014, 58\% of 
hospitals throughout Syria were either not functioning or were restricted in their ability to provide services. ${ }^{16}$ This number reflects healthcare facilities in the Aleppo, rural Damascus, Homs, Dara'a and Deir-ez-Zor governorates. WHO has reported severe shortages of medical supplies, scattered vaccination coverage, lack of capacity to address severe health needs and a critical shortage of health providers in Syria. ${ }^{15}$ In addition, medical providers have had to respond to the unprecedented use of toxic chemical agents used against civilians since the commencement of the war in December 2012, including a UN-confirmed sarin gas attack in April 2017 in Syria's northern Idlib province $^{17}$ as well as persistent allegations of chlorine gas and sarin use in Eastern Ghouta, ${ }^{18}{ }^{19}$ Syria throughout 2017 and 2018. ${ }^{172021}$

In Syria, the healthcare context is currently made up of three separate health 'systems': the first is run by the Syrian government and is restricted to areas it controls; a second system comprises an ad hoc collection of local and international non-governmental organisations (NGOs), local committees and relief agencies operating primarily within opposition-controlled areas and a third system is maintained by the Islamic State (ISIS) in areas it controls. ${ }^{22}$ One of these organisations is the diaspora Syrian American Medical Society (SAMS), ${ }^{23}$ a consortium of Syrian-American health professionals founded in 1998 as a professional society for networking for physicians of Syrian descent. In 2011, SAMS extended its capacity as a non-profit organisation in response to the Syrian crisis to provide support to healthcare staff and facilities, including providing aid and medical resources in hard-to-reach areas throughout Syria as well as ongoing training for healthcare professionals throughout the conflict. SAMS' operations are mainly in non-government controlled areas, including besieged areas, in northern and southern Syria.

Healthcare workers operating within opposition-controlled areas have struggled to provide services in the midst of a multidimensional crisis. ${ }^{24} \mathrm{~A}$ protracted war on healthcare infrastructure has led to inadequate access to basic necessities and a unprecedented humanitarian crisis. ${ }^{25-29}$ It is in this setting that health providers must make daily decisions at the micro-level, meso-level and macro-level of healthcare provision (eg, who receives care, which hospital to repair, where to target supplies). Conversely, in government-controlled areas the healthcare system has a premium on servicing its forces, with few health resources available for the civilian population, and coerced medical staff to remain and treat them. ${ }^{30}$

Obligations under international humanitarian law include requirements not to attack or interfere with healthcare services. ${ }^{31}$ According to the Geneva Conventions, parties to a conflict are obligated to 'respect and protect' wounded and sick people as well as medical facilities, personnel and transports. They must not directly attack them and are required to take steps to ensure that combat operations distinguish between military and civilian objects. ${ }^{32-34}$ Furthermore, health professionals may neither be punished for engaging in actions incompatible with medical ethics, nor compelled to do so. ${ }^{34}$ The bombing and use of chemical weapons against hospitals, use of missiles and sniper attacks on ambulances and arrest and torture of health workers for impartial care, all violate these obligations and constitute war crimes. ${ }^{30}$

Human rights obligations can be applied to health systems, including those in conflict, as an analytical tool to help better articulate and understand the responsibilities of states to respect-to refrain from directly interfering with a right; to protect-to prevent third-party interference with the enjoyment of a right and to fulfil-to take steps to ensure the fullest possible realisation of a right. ${ }^{31}$ The right to health, as defined by Article 12 of the International Covenant of Economic, Social and Cultural Rights and further articulated by UN Committee on Economic, Social and Cultural Rights in its General Comment 14, presses on states the obligations under the right to ensure the availability, accessibility, acceptability and quality of health facilities, goods and services. ${ }^{35}$ This study explores the complex challenges health workers face in providing care when healthcare services and personnel are themselves subjected to violence and forced to operate in the midst of ongoing human rights violations and war crimes.

\section{METHODS}

Qualitative research was conducted in October 2014 in Gaziantep with Syrian health workers attending a SAMS training in Turkey and on a separate occasion in July-August 2017 using secure online communication application with healthcare providers working in areas throughout Syria outside of government control. The study sought to: (1) describe attacks and interferences with healthcare occurring in opposition-controlled areas of Syria; (2) explore the challenges health workers face and the consequences for civilians' right to health and (3) to include the particular challenges faced by health workers who have responded to chemical attacks in northern Syria.

\section{Setting}

The majority of the qualitative fieldwork was collected in Gaziantep, Turkey, a city $97 \mathrm{~km}$ north of Aleppo, Syria. Gaziantep is host to Syrian and international NGOs, and is a humanitarian hub for cross-border support. Among the Syrian NGOs operating out of Gaziantep is SAMS, who partnered with the Johns Hopkins Bloomberg School of Public Health (JHSPH) on this project. SAMS provides routine medical trainings in Gaziantep for health professionals operating inside Syria, providing researchers the unique opportunity to speak directly to field staff with cross-border access. ${ }^{36}$ While the majority of the data was collected in-person in Gaziantep during the medical training in $2014(n=24)$, separate interviews $(n=5)$ were conducted with different sample of health professionals inside Syria via Wire, a secure online communication tool similar to Skype, in 2017 to understand the effect of the 
continuing violence inside Syria on healthcare; namely, the chemical attacks that occurred in early April of 2017 in Khan Shaykhun, a province of Idlib in northwestern Syria.

\section{Study population}

All participants were identified through purposive sampling methods, taking account of key informants' specialised knowledge and unique perspectives. Eligibility criteria required participants to be aged 18 years or older and a qualified health professional (formally trained doctors, nurses, dentists and laboratory, anaesthesiology and surgery technicians) with current or recent work-related experience in opposition-controlled areas of Syria. Participants were told the purpose of the study and how the information provided would be used and that participation was voluntary. Permission was sought and in all but one case granted for audio recording; no names or other identifiers were collected. With the exception of respondents who were fluent in English, interviews were conducted in Arabic either through an Arabic translator or Arabic-speaking interviewer. The 2014 interviewer (LR) concluded with a final sample of 27 when no new themes emerged. Three of the interviews conducted were excluded from this analysis due to poor audio quality, incomplete interview or declining audio recording. The respondents included 18 physicians (14 surgeons, 1 cardiologist, 2 anaesthesiologists and 1 paediatrician), 3 nurses, 3 dentists and the remaining 3 were laboratory, anaesthesiology and surgery technicians. An additional five interviews with new participants were conducted in 2017 by an Arabic-speaking interviewer (DR) to address experiences of medical staff (two surgeons, one pharmacist, one anaesthesiology technician and one nurse) inside Syria following a major chemical attack in northwestern Syria. Audio recordings were transcribed verbatim and triangulated with additional notes.

\section{Measurement and analysis}

Interviews followed a semi-structured interview guide that was developed in accordance with the aims of this study. This analysis reviews the challenges healthcare providers face and the constraints on patient care when approached through a right to health lens with a focus on: availability, understood as a functioning public health and healthcare facilities, goods and services, to include adequate hospitals and clinics, trained healthcare professionals and essential medicines; accessibility, the requirement that health facilities, goods and services be within safe physical reach for all sections of the population and quality, the entitlement that health facilities, goods and services must also be scientifically appropriate and of good quality, to include skilled medical personnel, scientifically approved and unexpired drugs and hospital equipment. ${ }^{35}$

Two independent reviewers (EC, KHAF) conducted the coding and analysis using an inductive and deductive approach to coding that relied on a priori topics, while still allowing for the emergence of new themes through a process of thematic analysis. ${ }^{18}$ First, researchers read through the transcripts to familiarise themselves with the data, three transcripts were then open-coded to delineate established and emergent categories. Coding categories were based on a priori topics around the right to health, and new concepts that emerged from the data. The researchers compared coded transcripts to identify discrepancies and further define the coding scheme. The codes were reviewed by KHAF, EC and LR. Clean transcripts were imported into HypeRESEARCH 3.7.2 and coded using the final scheme developed by the analysts.

\section{Ethical approval}

The study participants provided informed consent to be interviewed. All participants in accordance with Institutional Review Board procedures were explained the purpose of the research, were free to decline to participate and told of their liberty to withhold information they were uncomfortable to give. Finally, we assured and accorded them privacy, anonymity and confidentiality.

\section{Patient and public involvement}

No patients or members of the public were involved in the conduct of this research.

\section{RESULTS}

Findings from this study highlight major gaps in the availability, accessibility and quality of care available in large areas of Syria most effected and besieged by the ongoing conflict. An emergent theme related and connected to quality of care was the presence of acute mental health stressors and demoralising working conditions impacting on the well-being of health providers in this setting. Despite this, results point to key ways in which health providers on the ground have taken steps to fill these gaps so that civilians can continue to receive life-saving care.

\section{Sample characteristics}

Of the 29 participants in this sample, all but 2 were Syrian male health professionals. This is mainly due to the lack of female health professionals at the medical training in 2014, and the lack of female participants volunteering information for the 2017 interviews. The non-Syrian health professionals were female Americans who had recently worked in Syria, and were interviewed in 2014. The respondents had varied experience levels and medical professional backgrounds and had experience working in occupation-controlled areas of northwestern Syria (exact governorates excluded) (see Table 1). Below we present key findings emerging from our analysis of accounts of medical professionals in Syria.

\section{Availability}

The targeting of hospitals and ambulances in opposition-controlled and besieged areas has dramatically decreased the availability of healthcare. Participant descriptions capture both indiscriminate and targeted attacks, including the use of mortar shells, TNT 


\begin{tabular}{lc}
\hline Table 1 Participant demographics \\
\hline Total participants & $\mathbf{2 9}$ \\
\hline Gender & 27 \\
\hline Male & 2 \\
Female & \\
Nationality & 27 \\
\hline Syrian & 2 \\
\hline American & \\
\hline Profession & 13 \\
\hline Surgeon & 1 \\
Cardiologist & 2 \\
\hline Anaesthesiologist & 1 \\
\hline Paediatrician & 4 \\
\hline Nurse & 2 \\
\hline Dentist & 4 \\
\hline Technician & 2 \\
\hline Health coordinators & \\
\hline
\end{tabular}

(explosive) barrel bombs and nerve agents, often with multiple attacks on the same facility. A participant described constant bombardment of a hospital in Latakia:

Interviewer: "How many times has the hospital been hit in 3 months?"

Respondent: "Almost 90 times. It's on a daily basis.... The furthest was 100 metres. Sometimes it's 10 metres, 15 metres away from the hospital." (Interview 8, 2014)

Healthcare workers have responded to the constant attacks and attempts to obliterate healthcare availability by developing methods to protect themselves, their patients and their equipment. In response, nearly all participants described a common strategy of placing hospitals underground. However, doctors explained that even fortified hospitals underground or in a cave are vulnerable, in particular if exposed to a chemical attack, especially to heavy sarin gas:

"We operate in a fortified hospitals underground, but with chemical attacks all hospitals are susceptible to chemical attacks and getting destroyed." (Interview 1, 2017)

The ongoing conflict has restricted movement and limited the availability of health supplies. Medicines and equipment for trauma cases, the management of chronic diseases and treatable childhood diseases were highlighted as being in short supply:

"Because there are no vaccinations we now see polio and measles. All these diseases are different, some diseases need specific medication, and we haven't any." (Interview 12, 2014)
In particular, participants describing the medical response to the 2017 chemical attacks, highlighted that hospitals lacked sufficient supplies of appropriate antidotes to treat the nerve agent(s) civilians were exposed to:

"Our hospital wasn't equipped to treat chemical attacks, since we thought that chemical weapons were eradicated since 2013. Back then we brought big amount of Atropine to treat chemical attack victims but the medication expired and we never used it." (Interview 1, 2017)

The provision of medical supplies and medications, including protective equipment for chemical attacks, improved by 2017 through the work of humanitarian organisations. However, all participants described the continued scarcity of life-saving protective equipment and inadequate availability of specialist care. Given the high volume of serious traumatic injuries, availability of essential equipment and qualified physicians is essential to protect the right to health of those injured by conflict. However, in the absence of resources and training participant accounts highlighted altered standards of care implemented to preserve life:

"Lack of surgeons caused many cases to either be amputated after treatment, resulting in death or complications. A lack of instruments for orthopaedic and neurosurgery have also caused many complications. Despite this difficult reality, we are still doing 4500 surgeries each month." (Interview 2, 2014)

With respect to the chemical attacks, healthcare workers were also placed at increased risk of harm due to the lack of availability of appropriate safety equipment when treating patients exposed to chemical agents:

"Honestly, we still haven't received fully protective equipment. When the medical staff were affected and we saw how people were getting affected even when they thought they were protected ... this is when we started using masks. But even masks weren't good enough..." (Interview 2, 2017)

\section{Accessibility}

Attacks on hospitals during the 2017 sarin attacks limited patient access to hospitals at precisely the moment that it was most critical:

"We witnessed the aircraft striking the city six times, firing exactly 11 missiles. Once the aircraft were gone, we went to the hospital and we saw that the air strikes were targeting the hospital where the chemical attack victims were transferred to get treatment. By the time we arrived at the hospital, we found that all the staff had fled from fear, and a big part of the hospital was destroyed. One patient was undergoing a surgery, his blood was still on the operating table." (Interview 3, 2017) 
Even in cases where hospitals are not completely destroyed the impact of bombardments on healthcare access is profound, with many participants describing regular interruptions and closures. Fear of attacks on hospitals has an indirect but major impact on patient access to health services. As a participant explained:

"Lots of people don't dare to go to the hospital, because they know that the hospital has been targeted by the bombardment-five, six times. It's only those who are in grave need who will go to the hospital." (Interview 11, 2014)

For civilians who have been injured in attacks or who are unable to travel to a hospital for other reasons, medical care access is dependent on first responders or civilian transportation. However, ambulances are in short supply, in part due attacks on them, and the risk to first responders is great, as they are easy targets for aerial attacks:

"There were many cases when ambulance drivers have been attacked, especially at night in the dark. The aircraft see the lights of the ambulance and attack it." (Interview 2, 2014)

At times of acute crisis, such as the recent chemical attacks, lack of prompt access to facilities owing to long transport times and restricted capacity, has meant many additional civilian fatalities:

"There is no clear strategy for the health system tactically or operationally to deal with the number of injuries, and nerve injuries are a new topic for us. If there had been a medical point nearby, maybe one or two kilometres away from our hospital, we would have saved a lot of people." (Interview 5, 2017)

Finally, the difficulties and dangers of transporting supplies and equipment into besieged areas was highlighted as another access issue that poses severe risks for health workers. One participant reported that 28 staff from their hospital had been arrested while attempting to carry medicines and supplies to their hospital:

"Taking medicine into [town name], is a crime that is punished...they go to prison and nobody knows after that, of course it's torture." (Interview 7, 2014)

\section{Quality}

Makeshift hospitals (known as field hospitals) emerged in opposition-controlled areas as a result of the assault on health infrastructure in rebel held areas of Syria, replacing hospitals and clinics formerly serving Syria's population. These field hospitals are located in former factories, farms and schools. Although Syrian health workers and their supporters provide supplies and equipment to these field hospitals, in many of them it is extremely difficult to maintain standards of care, especially at times of mass casualties from attacks, as evidenced in participant descriptions:
"Everything is allowed in a field hospital. You can put the intravenous line in with alcohol - we do it all the time. You can do operations without sterilised materials, without anaesthesia machines." (Interview 15, 2014)

During the 2017 chemical attacks, some hospitals that had been closed down for safety reasons were reopened to deal with the overwhelming number of casualties:

"Most of the hospital was destroyed by an attack on (date excluded) and it was out of service, but because the other hospital couldn't deal with the large number of patient, they reactivated the emergency department. Even though it was very risky, just so they could receive some patients." (Interview 3, 2017)

Participants also reported that because of the high number of trauma cases, patients with other medical conditions were often left untreated. During the chemical attacks, triage decisions led to a lack of attention to the most vulnerable, including large numbers of affected children. Participants' accounts highlight that medical personnel such as dentists and anaesthesiology technicians are acquiring new skills to meet the chronic shortage of surgeons and anaesthesiologists, because so many health workers have fled Syria. Here, a participant describes how they performed a surgery without previous training:

[Interviewer: Part of your training was in that kind of surgery?] "No, it was just a minimal part of it, I was given just an overview of these types of surgeries, but out of necessity I've had to do these surgeries." (Interview 1, 2014)

Participants involved in treating patients in the most recent chemical attacks were frank in describing how ill prepared the medical sector has been, with training and equipment inadequate to meet the demands of the overwhelming crisis. This resulted in a highly variable quality of care at medical facilities:

"I think that medical providers barely saved $1-2 \%$ of the chemical attack victims, because the situation is totally different. We have no prior training, medical staff or equipment to deal with it. I believe that what we were able to provide was too little." (Interview 1, 2017)

The continued outward migration of healthcare providers from Syria, and resulting shortage in quality clinical care has also been exacerbated by the relentless targeting of healthcare services and recent chemical attacks:

"Some healthcare providers decided to stay in Turkey and not to go back to Syria until things are clearer, others said that the use of chemical weapons is something that will never stop. We won't be able to provide much and we might turn into patients ourselves, so 
medical staff were evaluating how beneficial they can be over there." (Interview 3, 2017)

\section{Health worker demoralisation}

The constant attacks to health infrastructure and the barriers to healthcare access, availability and quality that result, impact civilians who seek treatment and the health workers who provide care. Interviews highlighted a complex constellation of factors that impact health workers' day-to-day working conditions. As this participant described:

"You are working with bad health supplies and instruments, and short of financial support. We also have a great danger of being killed because of the constant bombings. All those factors put a great pressure on doctors... Especially the doctors that work for health organisations and in the opposition areas, they are under focus from the regime." (Interview 2, 2014)

Conditions remain violent, with participants interviewed following the 2017 chemical attacks drawing attention to the rising death toll among doctors and enduring sense of fatalism among those who remain:

"The past year Dr [name and date omitted] passed away [exposed to chemical agents while treating a patient] and another anesthesiologist passed away. There have been about 5-6 deaths from our medical staff within the organisation. The truth is that work in the northern countryside is considered suicide."

(Interview 5, 2017)

The stress of providing care during war is made worse because of the scarcity of health workers. Many participants reported that they work 24 hours a day because there are no other staff to relieve them of their duties. Additionally, participants described often feeling helpless, because of the number of people they could not assist. A participant explained health worker's relentless workload, coupled with the extreme trauma-related injuries they respond to:

"Sometimes it takes them from 8:00 in the morning till 12:00 in the evening doing operations only. And because of the lack of the staff they are obliged to stay in the hospital, moving from one operation to another, and sometimes they don't find time to even eat. This pressure they live under, and all the casualties they see, all the injuries, the beheaded, the limbs and everything. It puts them under very heavy pressure." (Interview 20, 2014)

Participants described the most recent chemical attacks as having a major impact on morale among health workers and their sense of isolation:

"Every single life we saved in the last year ended up dead in the chemical attack. At the end, death has become normal to the rest of the world, no one is reacting." (Interview 1, 2017)
"It had a big effect in creating a hopeless environment, feeling of hopelessness inside each healthcare provider." (Interview 3, 2017)

Participant accounts highlighted the mixed emotions generated by their work, as fear was offset only by a strong sense of professional commitment:

"Sometimes we have depression. But all of us believe that we must do this job-but all of us are afraid of some point where we're injured or killed..." (Interview 13, 2014)

In the absence of external support health workers look to one another, here a participant describes how they rejoice on days where their work does not bring with it the death of another colleague:

"After a barrel bomb falls we start dancing, the Arabian dancing. We are not dead, and if nobody is dead among us, we start dancing." (Interview 23, 2014)

Finally, another participant pointed to the absence and futility of psychological support and instead the role of their faith:

"What is good about psychological support after all what we have seen? In general, we don't get internal nor external psychological support. The staff that held up for 7 years have only God to depend on." (Interview 2, 2017)

\section{DISCUSSION}

To the authors' knowledge, this is the first research study to illuminate the experiences of indigenous health workers in Syria seeking to provide healthcare to the local population, while themselves under attack. Unlike international aid workers, whose experience have been extensively studied, local doctors, nurses and other health workers who remain in their country to try to relieve suffering have received far less attention in the context of research. This qualitative study of 29 health workers subjected to bombing and chemical attacks provides new insights into the overwhelming challenges they face, their persistence in trying to meet them and the psychological toll of carrying on. The bombing and chemical attacks have had far reaching implications beyond the observable violence and destruction of health infrastructure. These include the flight of health workers from Syria, even as population needs increase, reluctance of patients to seek needed care in hospitals and shortages of resources needed for patient care and health provider protection and security.

Attacks on hospitals, ambulances, health workers and the wounded and sick are not uncommon in armed conflict. In 2016, for example, such attacks took place in 23 countries, and bombing and shelling took place in 10 of them. ${ }^{9}$ Syria is unique, in part because of the number of 
sustained attacks on hospitals now numbering over 500 in a period of 7 years, alongside the rising number of chemical attacks. ${ }^{37}$ As has been found in other conflicts, ${ }^{31} 38-40$ our findings show that in Syria violence against healthcare has bred a climate of fear and insecurity, with devastating impacts on health-seeking behaviours and access including, civilian difficulties in reaching medical aid or avoidance of health facilities altogether. Participants described how their work to treat a suffering population was severely impeded by a lack of availability of essential equipment, facilities and treatments for chronic and infectious disease.

The challenges of maintaining standards of quality, interconnected to access and availability, was a central theme of the interviews, and constitutes a daily source of pressure and anxiety for those trying to provide care. Healthcare providers have had to cope with shortages in staff and equipment and overwhelming numbers of patients, rendering triage decisions impossibly hard. The large scale of chemical weapon attacks in facilities already compromised by violence against them has overwhelmed medical staffs. Despite efforts by many organisations to provide supplies, equipment and a safe environment, health workers have been forced to operate in conditions well below any standard of quality that existed prior to the conflict. The chemical attacks in 2017 in particular show the extent to which the use of prohibited weapons and extreme resource limitations impair health worker efforts to provide basic life-saving treatment, and the extreme threats posed to their own safety and well-being.

Organisations supporting medical care in Syria, such as SAMS, have responded to the crisis by providing training to health professionals on trauma care and response to chemical weapons attacks, offering protective equipment, antidotes for chemical attacks and constructing health facilities underground to protect them from bombs. These efforts, however, inevitably have limited impact in the face of the level of violence inflicted on health facilities and health workers. As one 2014 respondent said when asked what could be done to offer health workers in Syria support, he replied, 'Stop the bombing'. Only concerted action by the international community through the UN Security Council or otherwise could achieve that, and it has not been forthcoming over 7 years of conflict. Research on the effects of the Syrian conflict has described the lasting impact the migration of health workers on health systems and ultimately the civilian population remaining in Syria. ${ }^{25} 28$ Accounts from both 2014 and 2017 highlight the continued outward migration of health providers due to violence against them and the psychological toll taken by working in such circumstances. They also reveal how physician shortages have led to the self-training in specialisations for which doctors on the ground have no official certification. The need for medical personnel to act beyond their training inevitably has implications for the quality of care patients receive, and puts health providers not adequately trained under enormous pressure.
Participant accounts are consistent with other evidence, which together reveal that attacks on hospitals and medical providers are targeted and deliberate, and likely constitute war crimes. The data illustrate how violence against health workers and facilities undermined their ability to contribute to the realisation of the right to health, which imposes on states a number of core obligations to respect, protect and fulfil the health needs of the population, obligations that are non-derogable, even in times of conflict. ${ }^{41}{ }^{42}$ Syria has ratified the International Covenant on Economic, Social and Cultural Rights, and even though Syria does not control all areas of the country, it has an obligation both to refrain from taking actions to infringe the right to health and take affirmative steps to protect health workers and individuals seeking healthcare in those regions. ${ }^{42}$ Instead, the government is attacking hospitals and health workers, with UN human rights agencies continuing to confirm the severity of its violations of these rights.

Since we conducted interviews in 2014, attacks on hospitals and healthcare workers have escalated further with augmented findings from the 2017 chemical attacks illustrative of the severity of conditions on the ground. Chemical weapons have continuously been used by the Syrian government and its allies throughout the conflict, as confirmed by the UN chemical weapons watchdog, the Organization for the Prohibition of Chemical Weapons. ${ }^{17}$ The UN Security Council has repeatedly called on Syria and its allies to adhere to its legal obligation not to attack health facilities and health workers ${ }^{43}$ to no avail, and efforts by members of the Council to refer gross violations of international humanitarian law, including targeting of hospitals and health workers and the use of chemical weapons on civilians, to the International Criminal Court, were either blocked or denied by Russia.

\section{CONCLUSION}

This study shows the consequences for health practitioners who seek to provide medical care for populations where health systems are subjected to bombings and other forms of violence, including chemical attacks. It is remarkable that doctors and nurses continue to work in conditions of such danger, and how they have carried on despite dire shortages of staff and supplies. While they are resilient, they suffer enormously. The study underlines the consequences to health workers of the failure by the international community to take effective action to protect them from aerial assaults, chemical attacks and other forms of violence. It further underlines the imperative of taking strong steps to protect health workers in war and to focus on the needs of health professionals who struggle to continue to fulfil the right to health, even while under attack.

Those needs include: capacity building to respond to chemical attacks (including provision of correct antidotes and protective gear); removing barriers to accessing professional training (including continuing 
education abroad) and research informed trainings delivered remotely to ensure the provision of appropriately equipped psychologists and mental health supporters to provide care to healthcare workers. Finally, future research should continue to evaluate the staggering challenges faced by Syria's health professionals, affording them the opportunity to share their experience and knowledge.

\section{Limitations}

The findings are subject to a number of limitations. First, there is the potential for respondent bias (eg, specific geographic experience or gendered framing) due to a number of factors constraining the pool of available participants. The majority of participants were in Gaziantep for SAMS trainings in October 2014, and therefore data are limited to the experiences of a sample of health workers, collected within a short 5-day period, and then later in 2017 to those with specific knowledge of the chemical attacks. Furthermore, most participants were male despite outreach to both male and female health professionals currently inside Syria. This is mainly due to the scarcity of female health professionals attending the 2014 trainings (which includes cultural barriers and travel concerns for women from Syria into Turkey) and the lack of female representatives recommended to interview after the chemical attacks in 2017. To address this concern, future research on healthcare providers inside Syria should aim to include female health workers as well as interview questions that address gender-specific challenges among healthcare workers inside Syria. Additionally, the situation in northwestern Syria has changed and worsened since these data were collected. For this reason and to reflect more recent events, the research team were able to include updated data from health workers working in Syria in 2017. Finally, these findings do not apply to areas of the country controlled by the ISIS or to government-controlled areas. In government-controlled areas, the health system is understood to be largely intact, although capacity is variable, and the impact of the war can be felt through indiscriminate mortar attacks, emigration of senior physicians, travel restrictions and inconsistent supplies. ${ }^{30}$ However, access to information in these areas is extremely limited for researchers on-the-ground and was beyond the scope of this study. Despite these limitations, collectively accounts provide an opportunity to learn more in-depth details of the experiences of health workers operating in the Syrian conflict, to understand challenges to healthcare provision and to consider ways in which research can begin to support these providers.

Acknowledgements The authors would like to sincerely thank the dedicated healthcare workers in Syria for sharing their experiences for this research and to the Syrian American Medical Society for facilitating this research. The authors also thank Matthew Murray and Nicholas Degner for their contributions to the project.

Contributors KHAF and LR designed and conceptualised the study. LR, DR and MZS coordinated and carried out data collection. KHAF, EC and LR analysed and interpreted the data. KHAF led manuscript writing with contributions from EC, LR and MZS. All authors reviewed the final manuscript.
Funding Funding for the study was provided by the MacArthur Foundation.

Disclaimer The views and opinions expressed in this article are those of the authors and not necessarily those of the MacArthur Foundation who were not involved in any step in the design, collection, analysis or writing of this manuscript.

Competing interests LR reports grants from MacArthur Foundation for the conduct of the study; grants from Oak Foundation, grants from JK Kellogg Foundation, grants from Polak-Mainz Stichting, outside the submitted work; and Chair, Safeguarding Health in Conflict Coalition.

Patient consent Obtained.

Ethics approval The Johns Hopkins Bloomberg School of Public Health Institutional Review Board and a local review board approved research protocols for the 2014 and 2017 interviews.

Provenance and peer review Not commissioned; externally peer reviewed.

Data sharing statement All available data can be obtained from the corresponding author.

Open access This is an open access article distributed in accordance with the Creative Commons Attribution Non Commercial (CC BY-NC 4.0) license, which permits others to distribute, remix, adapt, build upon this work non-commercially, and license their derivative works on different terms, provided the original work is properly cited, appropriate credit is given, any changes made indicated, and the use is non-commercial. See: http://creativecommons.org/licenses/by-nc/4.0/.

\section{REFERENCES}

1. Amnesty International. Syria: The worst humanitarian crisis of our time. Syria: Amnesty International, 2015.

2. Fouad FM, Sparrow A, Tarakji A, et al. Health workers and the weaponisation of health care in Syria: a preliminary inquiry for The Lancet-American University of Beirut Commission on Syria. Lancet 2017;390:2516-26.

3. International Committee of the Red Cross. Ambulances and Prehospital services in Risk Situations. 2013 https://www.icrc.org/eng/ assets/files/publications/icrc-002-4104.pdf.

4. International Committee of the Red Cross. Ensuring the preparedness and security of health care facilities in armed conflicts and other emergencies. 2015 https://www.icrc.org/eng/assets/files/ publications/icrc-002-4239.pdf.

5. Abu Sa'Da C, Duroch F, Taithe B. Attacks on medical missions: overview of a polymorphous reality: the case of Médecins Sans Frontières. International Review of the Red Cross 2014;95:309-30.

6. Physicians for Human Rights. Beyond imagination: seven years of conflict in Syria. Syria: Physicians for Human Rights, 2018.

7. Chulov M, Shaheen K. Syrian medics 'subjected to extreme intimidation' after Douma attack. Syria: The Guardian, 2018.

8. Physicians for Human Rights. Anatomy of crisis: a map of attacks in health care in Syria. https://s3.amazonaws.com/PHR_syria_map/ web/index.html (accessed 17 Mar 2016).

9. Safeguarding Health in Conflict. IMPUNITY MUST END: attacks on health in 23 countries in conflict in 2016. Syria: Safeguarding Health in Conflict, 2017.

10. Human Rights Watch. Hospitals, health workers under attack. Syria: UN Security Council Should Strengthen Call for Justice, 2017.

11. Medecins Sans Frontiers. Healthcare is being annihilated amid intensified bombings in Syria's north-west. Syria: Medecins Sans Frontiers, 2017.

12. World Health Organization. Report on attacks on health care in emergencies: based on consolidated secondary Data 2014 and 2015. Geneva: World Health Organization, 2016.

13. Office of the United Nations High Commissioner for Human Rights. Deliberate deprivation of right to life, health. Syria: Office of the United Nations High Commissioner for Human Rights, 2016.

14. UN News. UN 'gravely concerned' over repeated attacks on hospitals, school. Syria: UN News, 2016.

15. World Health Organization East Mediterranean Regional Office. Regional situation report, June 2014, 2014.

16. World Health Organization Regional Office for the Eastern Mediterranian. Regional SitRep, September 2014 WHO Response to the Syrian Crisis, 2014.

17. Organisation for the Prohibition of Chemical Weapons. OPCW Factfinding mission confirms use of chemical weapons in Khan Shaykhun, 2017.

18. Physicians for Human Rights. Combating impunity: how we risk normalizing chemical weapons attacks and other war crimes in Syria, 2018. 
19. United Nations Human Rights Council. Press statement on the alleged use of chemical weapons in eastern Ghouta, 2018.

20. Syrian American Medical Society. A new normal: ongoing chemical weapons attacks in Syria, 2016.

21. Human Rights Watch. Death by chemicals: the Syrian government's widespread and systematic use of chemical weapons, 2017.

22. Coutts A, Fouad FM, Abbara A, et al. Responding to the Syrian health crisis: the need for data and research. Lancet Respir Med 2015;3:e8-9.

23. Syrian American Medical Society. About SAMS. https://www.samsusa.net/who-we-are/ (Accessed 24 April 2018).

24. Physicians for Human Rights. Doctors in the crosshairs: four years of attacks on health care in Syria, 2015.

25. Kherallah M, Alahfez T, Sahloul Z, et al. Health care in Syria before and during the crisis. Avicenna J Med 2012;2:51-3.

26. World Health Organization. Regional situation report, 2015.

27. Aylward RB, Alwan A. Polio in syria. Lancet 2014;383:489-91.

28. Cousins S. Syrian crisis: health experts say more can be done. Lancet 2015;385:931-4.

29. Devakumar D, Birch M, Rubenstein LS, et al. Child health in Syria: recognising the lasting effects of warfare on health. Confl Health 2015;9:34.

30. United Nations Human Rights Council. Independent international commission on the Syrian Arab Republic: assault on medical care in Syria, 2013.

31. Footer KHA, Rubenstein LS. A human rights approach to health care in conflict. International Review of the Red Cross 2013;95:167-87.

32. Breitegger A. The legal framework applicable to insecurity and violence affecting the delivery of health care in armed conflicts and other emergencies. International Rev of the Red Cross 2013;95:83-127.
33. Geneva Convention (IV) relative to the protection of civilian persons in time of war. Gevena, 1949.

34. Protocols additional to the Geneva conventions, 1949.

35. United Nations Committee on Economic Social and Cultural Rights (CESCR). General comment no. 14: the right to the highest attainable standard of health (Art. 12 of the Covenant): UN Committee on Economic, Social and Cultural Rights (CESCR), 2000.

36. Syrian American Medical Society. SAMS medical training for Syrian healthcare workers. https://www.sams-usa.net/medical-educationtraining/ (accessed 24 Apr 2018).

37. Rodriguez-Llanes JM, Guha-Sapir D, Schlüter BS, et al. Epidemiological findings of major chemical attacks in the Syrian war are consistent with civilian targeting: a short report. Confl Health $2018 ; 12$.

38. Footer $\mathrm{KH}$, Meyer S, Sherman SG, et al. On the frontline of eastern Burma's chronic conflict--listening to the voices of local health workers. Soc Sci Med 2014;120:378-86.

39. Save the Children Watchlist on Children and Armed Conflict. Every clinic is now on the frontline: the impact on children of attacks on health care in Afghanistan, 2016.

40. Save the Children Watchlist on Children and Armed Conflict. "Every day things are getting worse" the impact on children of attacks on healthcare in Yemen, 2017.

41. International Red Cross and Red Crescent Movement. Health care in danger project. http://healthcareindanger.org/hcid-project/ (accessed 1 Dec 2016).

42. United Nations General Assembly. Report of the special rapporteur on the right of everyone to the enjoyment of the highest attainable standard of physical and mental health, 2013

43. United Nations Security Council. Resolution, 2015. 